\title{
Mixed Convection Boundary Layer Flow on a Solid Sphere in a Nanofluid with the Presence of Viscous Dissipation
}

\author{
Muhammad Khairul Anuar Mohamed,2,*, Mohd Zuki Salleh², Anuar Ishak ${ }^{3}$ and Roslinda Nazar ${ }^{3}$ \\ ${ }^{I}$ Faculty of Engineering \& Technology, DRB-HICOM University of Automotive Malaysia, Peramu Jaya Industrial Area, \\ 26607 Pekan, Pahang, MALAYSIA \\ ${ }^{2}$ Centre for Mathematical Sciences, College of Computing \&Applied Sciences, Universiti Malaysia Pahang, \\ Lebuhraya Tun Razak, 26300 Gambang, Pahang, MALAYSIA. \\ ${ }^{3}$ School of Mathematical Sciences, Faculty of Science and Technology, Universiti Kebangsaan Malaysia,
}

43600 UKM Bangi, Selangor, MALAYSIA

\begin{abstract}
The present study considers the mathematical modelling of mixed convection boundary layer flow and heat transfer on a solid sphere immersed in a nanofluid with viscous dissipation effects. The transformed partial differential equations are solved numerically using the Keller-box method. Numerical solutions are obtained for the reduced Nusselt number, the reduced Sherwood number and the reduced skin friction coefficient. The features of the flow characteristics for various values of Prandtl number, the mixed convection parameter, the Brownian motion parameter, the thermophoresis parameter, the Lewis number, and the Eckert number are analysed and discussed. It is found that the increment of the Brownian motion parameter and the thermophoresis parameter reduced the heat transfer rate at the surface.
\end{abstract}

Keywords: Heat transfer, mixed convection, nanofluid, solid sphere, viscous dissipation

\section{INTRODUCTION}

Convection is a motion that happens within a fluid from a warmer area, which is less dense, to a cooler area, which has slower moving molecules. This phenomenon usually involved medium, liquid or air, such as electrolyte, water and oil. The base fluids like water, and oil which have low thermal conductivity can be engineered by colloidal suspensions of nanoparticles in order to enhance the thermal conductivity. This upgraded fluid is called nanofluid, which was first termed by Choi (1995). Nanofluid is used widely in automotive applications for example as engine oil, brake fluid, radiator coolant, fuel additive, and battery devices. This situation attracted researchers to deeply study the heat and flow characteristic of nanofluid.

The objective of the present study is to solve the mathematical model for the mixed convection boundary layer flow on a solid sphere immersed in a nanofluid with the presence of viscous dissipation. It is known that Yuge (1960) was the first who considered the experimental study on the mixed convection boundary layer and heat transfer on the sphere surface. Study on sphere surface continues until $21^{\text {st }}$ century for example from the works by Nazar et. al., (2002; 2003)and Salleh et. al., (2010a; 2010b)who extended this study to a micropolar fluid with different boundary conditions, namely the constant wall temperature, constant heat flux, and the Newtonian heating, respectively.

Recent works in the same topic include Mohamed et al. (2016), Aziz et. al., (2017), Ashraf et. al., (2017), Sheikholeslami et. al., (2018) andYuan et. al., (2018)who investigated the free, forced and mixed convection flow on a sphere surface in viscous fluid, water-based nanofluids

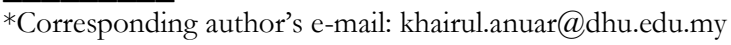


and viscoelastic micropolar fluids with the presence of viscous dissipation, magnetic field and thermal radiation effects, respectively.

\section{MATHEMATICAL FORMULATIONS}

Consider a solid sphere with radius $a$ heated to a constant temperature $T_{w}$ embedded in a nanofluid with ambient temperature $T_{\infty}$. The orthogonal coordinates $\bar{x}$ is measured along the sphere surface, starting from the lower stagnation point $\bar{x}=0$ and $\bar{y}$ is measured along the distance normal to the surface of the sphere. The radial distance from the symmetrical axis to the surface is denoted by $\bar{r}(\bar{x})$. The dimensional boundary layer equations are:

$$
\begin{aligned}
& \frac{\partial}{\partial \bar{x}}(\bar{r} \bar{u})+\frac{\partial}{\partial \bar{y}}(\bar{r} \bar{v})=0, \\
& \bar{u} \frac{\partial \bar{u}}{\partial \bar{x}}+\bar{v} \frac{\partial \bar{u}}{\partial \bar{y}}=\bar{u}_{e} \frac{d \bar{u}_{e}}{d \bar{x}}+v \frac{\partial^{2} \bar{u}}{\partial \bar{y}^{2}}+ \\
& g \beta\left(T-T_{\infty}\right) \sin \frac{\bar{x}}{a}+g \beta_{c}\left(C-C_{\infty}\right) \sin \frac{\bar{x}}{a}, \\
& \bar{u} \frac{\partial T}{\partial \bar{x}}+\bar{v} \frac{\partial T}{\partial \bar{y}}=\alpha \frac{\partial^{2} T}{\partial \bar{y}^{2}}+ \\
& \tau\left[D_{B} \frac{\partial C}{\partial \bar{y}} \frac{\partial T}{\partial \bar{y}}+\frac{D_{T}}{T_{\infty}}\left(\frac{\partial T}{\partial \bar{y}}\right)^{2}\right]+\frac{\mu}{\rho C_{p}}\left(\frac{\partial \bar{u}}{\partial \bar{y}}\right)^{2}, \\
& \bar{u} \frac{\partial C}{\partial \bar{x}}+\bar{v} \frac{\partial C}{\partial \bar{y}}=D_{B} \frac{\partial^{2} C}{\partial \bar{y}^{2}}+\frac{D_{T}}{T_{\infty}} \frac{\partial^{2} T}{\partial \bar{y}^{2}},
\end{aligned}
$$

with boundary conditions

$$
\begin{gathered}
\bar{u}(\bar{x}, 0)=\bar{v}(\bar{x}, 0)=0, T(\bar{x}, 0)=T_{w}, C(\bar{x}, 0)=C_{w}, \\
\bar{u}(\bar{x}, \infty) \rightarrow \bar{u}_{e}(x), T(\bar{x}, \infty) \rightarrow T_{\infty}, C(\bar{x}, \infty) \rightarrow C_{\infty}(5)
\end{gathered}
$$

where $\bar{u}$ and $\bar{v}$ are the velocity components along the $\bar{x}$ and $\bar{y}$ axes, respectively. $\bar{u}_{e}(x)$ is the local free stream velocity, $\mu$ is the dynamic viscosity, $v$ is the kinematic viscosity, $g$ is the gravity acceleration, $\beta$ is the thermal expansion coefficient, $\beta_{c}$ is the concentration expansion coefficient, $T$ is the local temperature, $\rho$ is the fluid density and $C_{p}$ is the specific heat capacity at a constant pressure. $\tau$ is the ratio of the effective heat capacity of the nanoparticle material and the heat capacity of the nanofluid while $D_{B}$ and $D_{T}$ are Brownian diffusion and thermophoresis diffusion coefficients, respectively.

Furthermore, $C$ is the nanoparticle volume fraction, $C_{w}$ is the nanoparticle volume fraction at the surface and $C_{\infty}$ is the ambient nanoparticle volume fraction. Further, it is given that

$$
\bar{u}_{e}(x)=U_{\infty} \sin \left(\frac{\bar{x}}{a}\right), \quad \bar{r}(\bar{x})=a \sin \left(\frac{\bar{x}}{a}\right) .
$$

Next, the governing non-dimensional variables are introduced as follows:

$$
\begin{gathered}
x=\frac{\bar{x}}{a}, y=\operatorname{Re}_{x}^{1 / 2} \frac{\bar{y}}{a}, u=\frac{\bar{u}}{U_{\infty}}, \\
v=\operatorname{Re}_{x}^{1 / 2} \frac{\bar{v}}{U_{\infty}}, r=\frac{\bar{r}}{a}, u_{e}(x)=\frac{\bar{u}_{e}(x)}{U_{\infty}}, \\
\theta(\eta)=\frac{T-T_{\infty}}{T_{w}-T_{\infty}}, \phi(\eta)=\frac{C-C_{\infty}}{C_{w}-C_{\infty}},
\end{gathered}
$$

with

$$
\psi=x r(x) f(x, y), \theta=\theta(x, y), \phi=\phi(x, y),
$$

where $\quad \psi$ is the stream function defined as $u=\frac{1}{r} \frac{\partial \psi}{\partial y}$ and $v=-\frac{1}{r} \frac{\partial \psi}{\partial x}$ which identically satisfies Eq. (1). $\theta$ and $\phi$ are the rescaled dimensionless temperature and nanoparticle volume fraction of the fluid while $\operatorname{Re}_{x}=\frac{U_{\infty} a}{v}$ is the Reynolds number.

Substituting Eqs. (7) and(8) into Eqs. (1)-(5), the following non-dimensional partial differential equations are obtained:

$$
\begin{gathered}
\frac{\partial^{3} f}{\partial y^{3}}+\left(1+\frac{x}{\sin x} \cos x\right) f \frac{\partial^{2} f}{\partial y^{2}}-\left(\frac{\partial f}{\partial y}\right)^{2}+ \\
\left(\frac{9}{4} \cos x+\lambda \theta+\omega \phi\right) \frac{\sin x}{x}=x\left(\frac{\partial f}{\partial y} \frac{\partial^{2} f}{\partial x \partial y}-\frac{\partial f}{\partial x} \frac{\partial^{2} f}{\partial y^{2}}\right)
\end{gathered}
$$

$$
\begin{gathered}
\frac{1}{\operatorname{Pr}} \frac{\partial^{2} \theta}{\partial y^{2}}+\left(1+\frac{x}{\sin x} \cos x\right) f \frac{\partial \theta}{\partial y}+N_{b} \frac{\partial \phi}{\partial y} \frac{\partial \theta}{\partial y}+ \\
N_{t}\left(\frac{\partial \theta}{\partial y}\right)^{2}=x\left(\frac{\partial f}{\partial y} \frac{\partial \theta}{\partial x}-\frac{\partial f}{\partial x} \frac{\partial \theta}{\partial y}-x E c\left(\frac{\partial^{2} f}{\partial y^{2}}\right)^{2}\right)
\end{gathered}
$$


(10)

$$
\begin{gathered}
\frac{\partial^{2} \phi}{\partial y^{2}}+\frac{N_{t}}{N_{b}} \frac{\partial^{2} \theta}{\partial y^{2}}+\left(1+\frac{x}{\sin x} \cos x\right) \text { Lef } \frac{\partial \phi}{\partial y}= \\
x L e\left(\frac{\partial f}{\partial y} \frac{\partial \phi}{\partial x}-\frac{\partial f}{\partial x} \frac{\partial \phi}{\partial y}\right) .
\end{gathered}
$$

where $\operatorname{Pr}=\frac{v}{\alpha} \quad$ is the Prandtl number, $N_{b}=\frac{\tau D_{B}\left(C_{w}-C_{\infty}\right)}{v}$ is the Brownian motion parameter, $N_{t}=\frac{\tau D_{T}\left(T_{w}-T_{\infty}\right)}{T_{\infty} V}$ is the thermophoresis parameter and $E c=\frac{U_{\infty}^{2}}{C_{p}\left(T_{w}-T_{\infty}\right)}$ is the Eckert number. $\lambda=\frac{G r}{\operatorname{Re}_{x}^{2}}$ is the mixed convection parameter, $\omega=\frac{G r_{c}}{\operatorname{Re}_{x}^{2}} \quad$ is the concentration mixed convection parameter with $G r=\frac{g \beta\left(T_{w}-T_{\infty}\right) a^{3}}{v^{2}}$ is the Grashof number and $G r_{c}=\frac{g \beta_{c}\left(C_{w}-C_{\infty}\right) a^{3}}{v^{2}}$ is the modify Grashof number with considering the concentration which also known as mass transfer Grashof number. Further, $L e=\frac{v}{D_{B}}$ is the Lewis number. The boundary conditions (5) become

$$
\begin{gathered}
f(x, 0)=0, \quad \frac{\partial f}{\partial y}(x, 0)=0, \quad \theta(x, 0)=1, \quad \phi(x, 0)=1, \\
\frac{\partial f}{\partial y}(x, \infty) \rightarrow \frac{3}{2} \frac{\sin x}{x}, \quad \theta(x, \infty) \rightarrow 0, \quad \phi(x, \infty) \rightarrow 0 .
\end{gathered}
$$

The physical quantities of interest are the skin friction coefficient $C_{f}$, the local Nusselt number $N u_{x}$ and the local Sherwood number $S h_{x}$ which reduced to(Mohamed et al., 2018):

$$
\begin{array}{r}
C_{f} \operatorname{Re}_{x}^{1 / 2}=\left(x \frac{\partial^{2} f}{\partial y^{2}}\right)_{\bar{y}=0}, \quad N u_{x} \operatorname{Re}_{x}^{-1 / 2}=-\left(\frac{\partial \theta}{\partial y}\right)_{\bar{y}=0} \\
\text { and } S h_{x} \operatorname{Re}_{x}^{-1 / 2}=-\left(\frac{\partial \phi}{\partial y}\right)_{\bar{y}=0}
\end{array}
$$

\section{RESULTS AND DISCUSSIONS}

The partial differential equations (9)-(11) subject to the boundary conditions (12) were solved numerically with seven parameters considered, namely the Prandtl number $\operatorname{Pr}$, the mixed convection parameter $\lambda$, the concentration mixed convection parameter $\omega$, the Brownian motion parameter $N_{b}$, thermophoresis parameter $N_{t}$, Lewis number $L e$ and the Eckert number $E c$. In order to validate the numerical results obtained, the comparison with previously published results has been made. Table 1 shows the comparison values of the reduced Nusselt number $N u_{x} \operatorname{Re}_{x}^{-1 / 2}$ for various values of $x$. It was found that the result is in a very good agreement, hence it is concluded that the Keller-box method works efficiently in solving the present problem thus providing the accurate results.

Tables 2 presents the values of the reduced Nusselt number $N u_{x} \operatorname{Re}_{x}^{-1 / 2}$ with various values of $x$ and $\lambda$. From Table 2, it was found that $N u_{x} \mathrm{Re}_{x}^{-1 / 2}$ is a decreasing function of $x$. It is a physically indicates that the convective heat transfer capability is reduced along the sphere surface. As $\lambda$ increases, it was found that $N u_{x} \operatorname{Re}_{x}^{-1 / 2}$ also increases. Further, it is understood that a decrease in $\lambda$ accelerates the separation layer which causes turbulence flow. This situation reduces the occurrence range of laminar boundary layer flow on the sphere surface.

Next, Figures 1 to 6 show the variations of the reduced Nusselt number $N u_{x} \mathrm{Re}_{x}^{-1 / 2}$, reduced Sherwood number $S h_{x} \operatorname{Re}_{x}^{-1 / 2}$ and reduced skin friction coefficient $C_{f} \operatorname{Re}_{x}^{1 / 2}$ against $x$ for various values of pertinent parameters discussed, respectively. From the numerical results obtained, it was found that most calculations encounter singularity after $x=2 \pi / 3$. Furthermore, there are also the calculations that give negative values of $N u_{x} \operatorname{Re}_{x}^{-1 / 2}$ which denotes as the reverse direction of flow convection. Therefore, in this study, the discussion is limited from lower stagnation region $(x=0)$ until 
$x=2 \pi / 3$ with only considering the positive value of $N u_{x} \operatorname{Re}_{x}^{-1 / 2}$.

From Figures 1 to 3 , it was found that $N u_{x} \operatorname{Re}_{x}^{-1 / 2}$ is a decreasing function of $x$ for $E c \geq 0$. The increase of $N_{t}, N_{b}, L e$ and $\omega$ contributes to a decrease in $N u_{x} \operatorname{Re}_{x}^{-1 / 2}$. Similar behavior occur in Figures 2 where the increase of $E c$ accelerates $N u_{x} \operatorname{Re}_{x}^{-1 / 2}$ to approach $\mathrm{o}$ and thus gives drastic reduction in convective heat transfer process. Further, it is concluded that the increase of $E c$ accelerates the layer separation. In Figure 3, the huge increase of Le only gives a small impact on $N u_{x} \operatorname{Re}_{x}^{-1 / 2}$. The effect of Le on $N u_{x} \operatorname{Re}_{x}^{-1 / 2}$ is more significant with large $\operatorname{Pr}$. Meanwhile, the increase of $\operatorname{Pr}$ gives an increase on $N u_{x} \operatorname{Re}_{x}^{-1 / 2}$ at the stagnation region $(x=0)$. This situation goes contrary as the flow passes to the middle of the sphere surface.

Table 1. Comparison values of $N u_{x} \operatorname{Re}_{x}^{-1 / 2}$ with previously published results for various values of $\lambda$ when

$$
\operatorname{Pr}=0.7, N_{b}=N_{t}=\omega=E c=L e=0 .
$$

\begin{tabular}{cccc}
\hline$\lambda$ & Nazar et al. (2003) & Salleh et al. (2010b) & Present \\
\hline-4.0 & 0.6534 & 0.6528 & 0.6528 \\
-3.0 & 0.7108 & 0.7099 & 0.7095 \\
-2.0 & 0.7529 & 0.7519 & 0.7516 \\
-1.0 & 0.7870 & 0.7860 & 0.7858 \\
-0.5 & 0.8021 & 0.8010 & 0.8009 \\
0.0 & 0.8162 & 0.8150 & 0.8150 \\
1.0 & 0.8463 & 0.8406 & 0.8406 \\
2.0 & 0.8648 & 0.8636 & 0.8636 \\
3.0 & 0.8857 & 0.8845 & 0.8845 \\
4.0 & 0.9050 & 0.9038 & 0.9038 \\
5.0 & 0.9230 & 0.9217 & 0.9217 \\
6.0 & 0.9397 & 0.9385 & 0.9385 \\
\hline
\end{tabular}

Next, Figures 4 and 5 present the variation of $S h_{x} \operatorname{Re}_{x}^{-1 / 2}$ for various values of $L e, \lambda, E c$ and $\omega$. Again, it can be concluded the $S h_{x} \operatorname{Re}_{x}^{-1 / 2}$ decreases along $x$ for various $L e, \lambda, \omega$ and certain values of $E c$. It is physically a sign of reducing in convective mass transferability as the flow passes the sphere surface. Further, the increase of $L e, \lambda, E c$ and $\omega$ results in the increase of $S h_{x} \mathrm{Re}_{x}^{-1 / 2}$.In Figure 4, it is worth mentioning that $S h_{x} \operatorname{Re}_{x}^{-1 / 2}$ is unique for any $E c$ at the stagnation region, which is clear from Eq. (10). This unique polar shows that $E c$ has no influence at the stagnation region $(x=0)$. Meanwhile from Figure 5 , it is suggested that the influence of $L e$ is more pronounced at the stagnation region. This may be due to the no-slip properties or no velocity gradient at the stagnation region thus it contributes to the maximum capability in convective mass transfer on the sphere surface. 
Lastly, Figures 6 and 7 illustrate the variation of $C_{f} \operatorname{Re}_{x}^{1 / 2}$ for various values of $L e, \lambda, E c$ and $\omega$. From both figures, the solution is unique at the stagnation region before spreading up as $x$ increases. It is seen that $C_{f} \mathrm{Re}_{x}^{1 / 2}$ increases from stagnation point to a certain point then decreases back such a quadratic curve. Next, noticed that the increase of $\lambda, E c$ and $\omega$ results in the increase in $C_{f} \operatorname{Re}_{x}^{1 / 2}$ while Le does oppositely. Further, it is shown in Figure 7 that the increase in $\lambda$ delayed layer separation.

Table 2. Values of $N u_{x} \operatorname{Re}_{x}^{-1 / 2}$ for $x$ and $\lambda$ when

$\operatorname{Pr}=\omega=1, N_{b}=N_{t}=E c=0.1$ and $L e=10$.

\begin{tabular}{ccccccc}
\hline$x / \lambda$ & $\mathbf{- 1 . 0}$ & $\mathbf{- 0 . 5}$ & $\mathbf{0}$ & $\mathbf{0 . 5}$ & $\mathbf{1 . 0}$ & $\mathbf{2 . 0}$ \\
\hline 0 & 0.8090 & 0.8229 & 0.8360 & 0.8487 & 0.8601 & 0.8820 \\
$\pi / 18$ & 0.8002 & 0.8139 & 0.8268 & 0.8388 & 0.8503 & 0.8715 \\
$\pi / 9$ & 0.7752 & 0.7883 & 0.8004 & 0.8117 & 0.8222 & 0.8415 \\
$\pi / 6$ & 0.7361 & 0.7483 & 0.7594 & 0.7694 & 0.7786 & 0.7948 \\
$2 \pi / 9$ & 0.6863 & 0.6975 & 0.7073 & 0.7158 & 0.7233 & 0.7356 \\
$5 \pi / 18$ & 0.6290 & 0.6397 & 0.6483 & 0.6552 & 0.6609 & 0.6688 \\
$\pi / 3$ & 0.5690 & 0.5798 & 0.5878 & 0.5935 & 0.5975 & 0.6011 \\
$7 \pi / 18$ & 0.5040 & 0.5168 & 0.5251 & 0.5302 & 0.5329 & 0.5326 \\
$4 \pi / 9$ & 0.4336 & 0.4523 & 0.4632 & 0.4690 & 0.4713 & 0.4681 \\
$\pi / 2$ & 0.3471 & 0.3832 & 0.4011 & 0.4100 & 0.4134 & 0.4092 \\
$5 \pi / 9$ & & 0.2975 & 0.3349 & 0.3515 & 0.3583 & 0.3557 \\
$11 \pi / 18$ & & & 0.2541 & 0.2899 & 0.3042 & 0.3064 \\
$2 \pi / 3$ & & & & 0.2182 & 0.2483 & 0.2599 \\
$13 \pi / 18$ & & & & 0.1008 & 0.1879 & 0.2145 \\
$7 \pi / 9$ & & & & & 0.1190 & 0.1697 \\
$5 \pi / 6$ & & & & & & 0.1257 \\
$8 \pi / 9$ & & & & & & 0.0833 \\
$17 \pi / 18$ & & & & & & 0.0436 \\
\hline
\end{tabular}

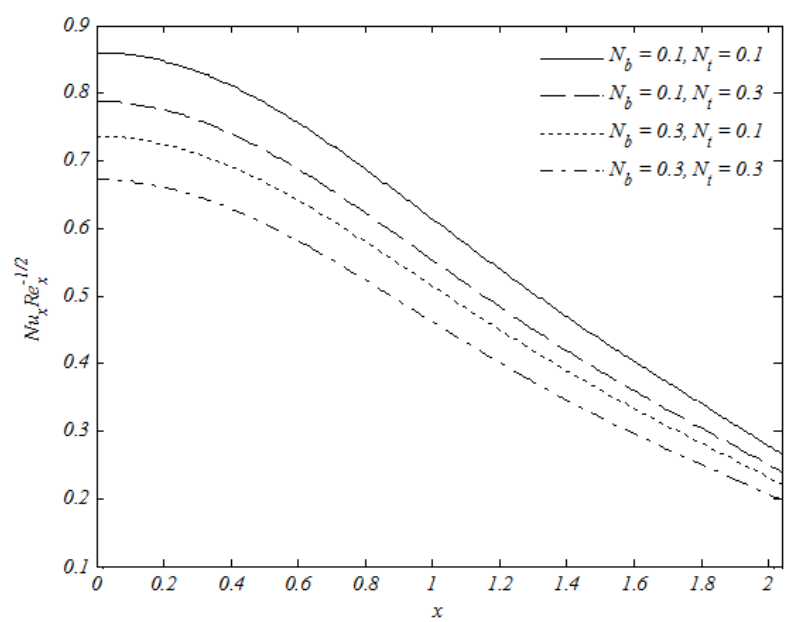

Figure 1. Variation of $N u_{x} \operatorname{Re}_{x}^{-1 / 2}$ with $N_{b}$ and $N_{t}$ when $\operatorname{Pr}=\omega=\lambda=1, E c=0.1$ and $L e=10$.

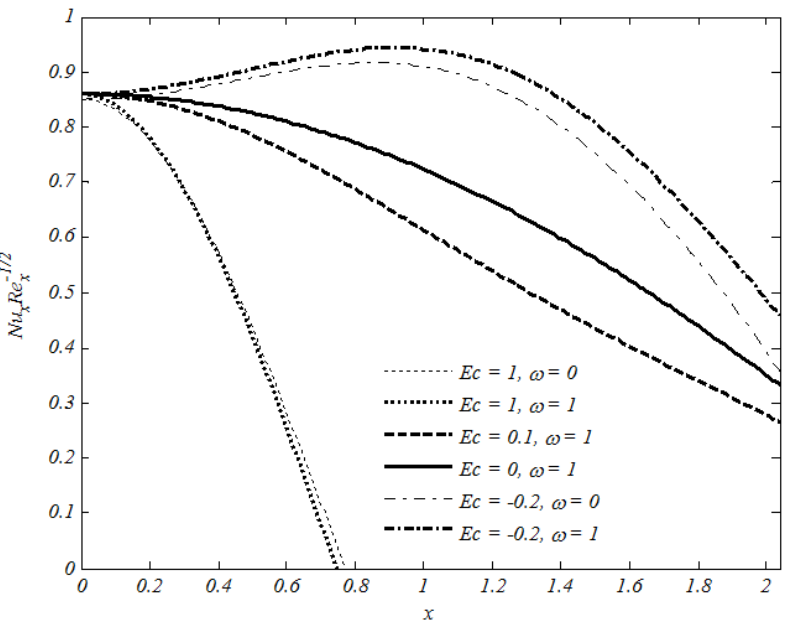

Figure 2. Variation of $N u_{x} \operatorname{Re}_{x}^{-1 / 2}$ with $E c$ and $\omega$ when

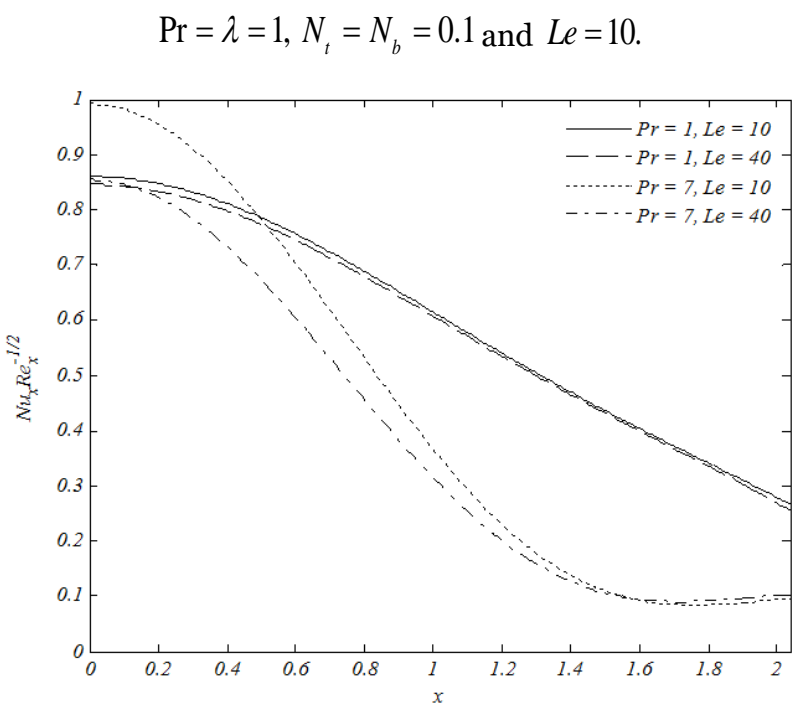

Figure 3. Variation of $N u_{x} \operatorname{Re}_{x}^{-1 / 2}$ with $\operatorname{Pr}$ and $L e$ when $\lambda=\omega=1$ and $N_{b}=N_{t}=E c=0.1$. 


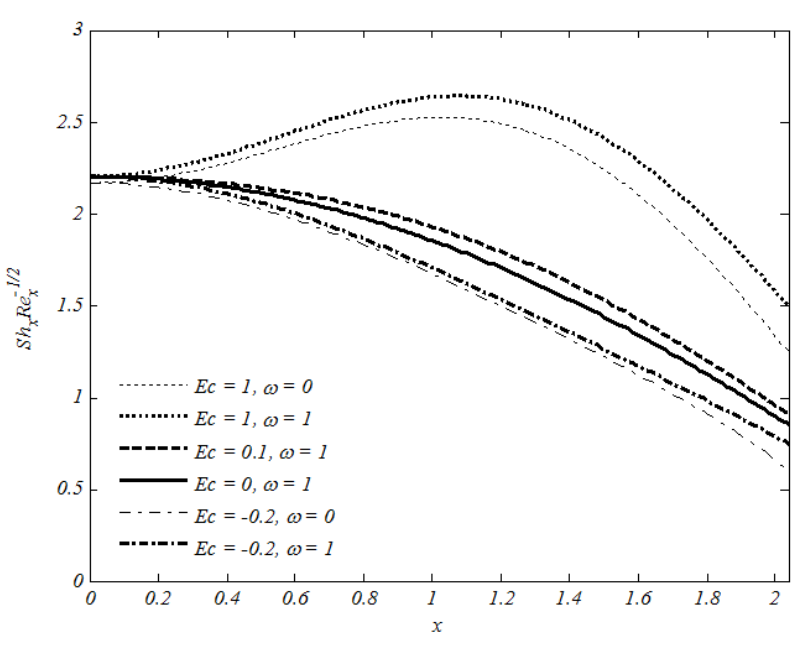

Figure 4. Variation of $S h_{x} \operatorname{Re}_{x}^{-1 / 2}$ with $E c$ and $\omega$ when

$$
\operatorname{Pr}=\lambda=1, N_{t}=N_{b}=0.1 \text { and } L e=10 .
$$

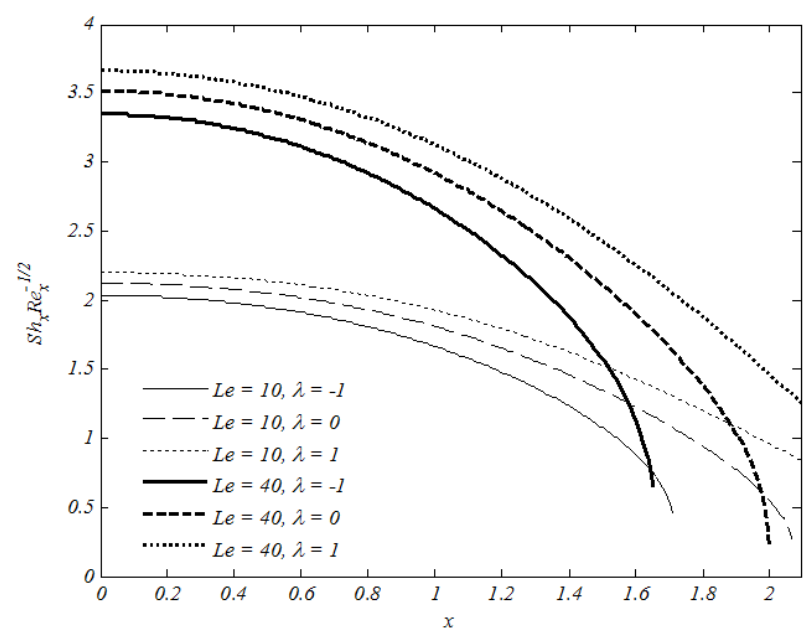

Figure 5. Variation of $S h_{x} \operatorname{Re}_{x}^{-1 / 2}$ with $L e$ and $\lambda$ when

$$
\operatorname{Pr}=\omega=1 \text { and } N_{b}=N_{t}=E c=0.1 \text {. }
$$

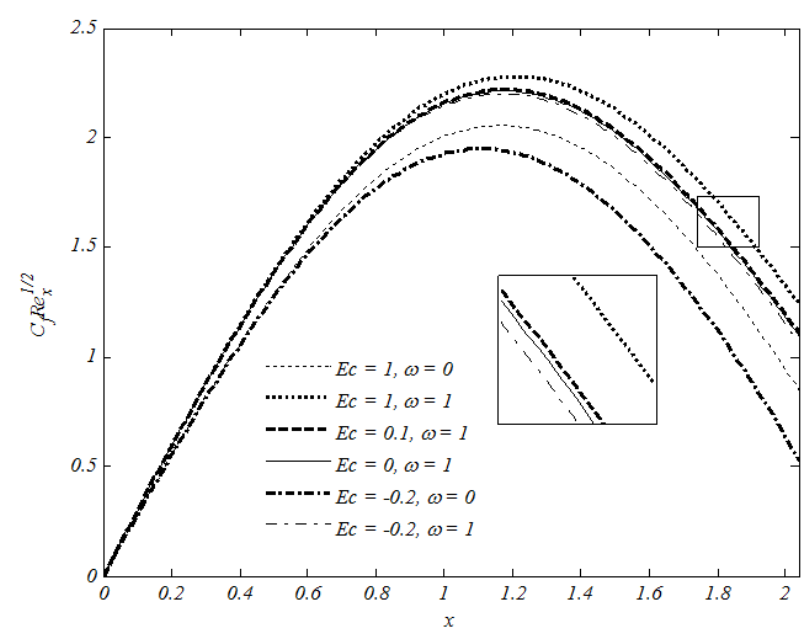

Figure 6. Variation of $C_{f} \operatorname{Re}_{x}^{1 / 2}$ with $E c$ and $\omega$ when

$$
\operatorname{Pr}=\lambda=1, N_{t}=N_{b}=0.1 \text { and } L e=10 .
$$

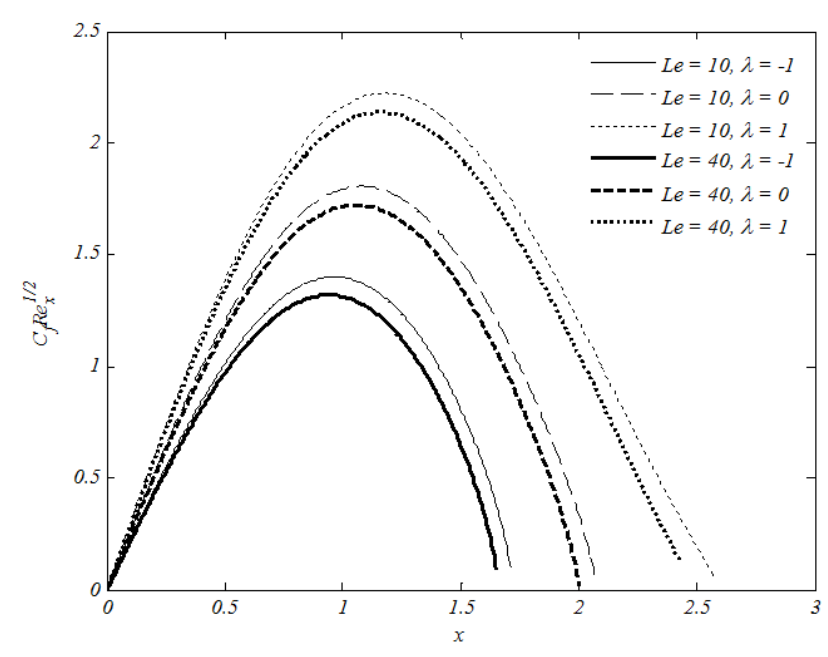

Figure 7. Variation of $C_{f} \operatorname{Re}_{x}^{1 / 2}$ with $L e$ and $\lambda$ when $\operatorname{Pr}=\omega=1$ and $N_{b}=N_{t}=E c=0.1$.

\section{CONCLUSION}

In this study, the problem of mixed convection boundary layer flow and heat transfer on a solid sphere embedded in a nanofluid in the presence of viscous dissipation was solved numerically. It was shown how the Prandtl number Pr, the mixed convection parameter $\lambda$, the concentration mixed convection parameter $\omega$, the Brownian motion parameter $N_{b}$, the thermophoresis parameter $N_{t}$, the Lewis number $L e$ and the Eckert number $E c$ influenced the local Nusselt number, the local Sherwood number, and the skin friction coefficient. It was found that the Nusselt number has a negative function along the sphere surface.

It was observed that the small increment of the Brownian motion parameter and thermophoresis parameter gave a large reduction on Nusselt number while large changes in Lewis number gave a small reduction. In considering the effect of viscous dissipation, it is suggested that the increase of Eckert number results in the increase of both the Sherwood number and the local skin friction coefficient. Lastly, from the numerical computation, it is understood that the decrease in mixed convection parameter and concentration mixed convection parameter accelerated the separation layer which causes the turbulence flow. This situation reduces the occurrence range of laminar boundary layer flow on the sphere surface. This indicates that the occurrence of separation flow on opposing flow is faster than the assisting flow. 


\section{ACKNOWLEDGEMENT}

The authors would like to express sincere gratitude to the DRB-HICOM University of Automotive Malaysia and Universiti Malaysia Pahang for financial and facilities support.

\section{REFERENCES}

Ashraf, M., Fatima, A. \& Gorla, R. S. R. 2017, Periodic momentum and thermal boundary layer mixed convection flow around the surface of a sphere in the presence of viscous dissipation. Canadian Journal of Physics, 95(10), 976-986.

Aziz, L. A., Kasim, A. R. M., Salleh, M. Z., Yusoff, N. S. \& Shafie, S. 2017, Magnetohydrodynamics effect on convective boundary layer flow and heat transfer of viscoelastic micropolar fluid past a sphere. Journal of Physics: Conference Series, 890(1), 012003.

Choi, S. U. S. 1995, Enhancing thermal conductivity of fluids with nanoparticles. American Society of Mechanical Engineers, 231, 99-105.

Mohamed, M. K. A., Sarif, N. M., Noar, N. A. Z. M., Salleh, M. Z. \& Ishak, A. 2016, Viscous Dissipation Effect on the Mixed Convection Boundary Layer Flow towards Solid Sphere. Transactions on Science and Technology, 3(1-2), 59-67.

Mohamed, M. K. A., Sarif, N. M., Noar, N. A. Z., Salleh, M. Z. \& Ishak, A. 2018, Mixed convection boundary layer flow on a horizontal circular cylinder in a nanofluid with viscous dissipation effect. Malaysian Journal of Fundamental and Applied Sciences, 14(1), 32-39.

Nazar, R., Amin, N. \& Pop, I. 2002, Mixed convection boundary layer flow from a sphere with a constant surface heat flux in a micropolar fluid. Journal of Energy Heat and Mass Transfer, 24(3), 195-212.

Nazar, R., Amin, N. \& Pop, I. 2003, Mixed convection boundary layer flow about an isothermal sphere in a micropolar fluid. International Journal of Thermal Sciences, 42(3), 283-293.
Salleh, M. Z., Nazar, R. \& Pop, I. 2010, Mixed Convection Boundary Layer Flow from a Solid Sphere with Newtonian Heating in a Micropolar Fluid. SRX Physics, 2010, 736039.

Salleh, M. Z., Nazar, R. \& Pop, I. 2010, Mixed convection boundary layer flow about a solid sphere with Newtonian heating. Archives of Mechanics, 62(4), 283303.

Sheikholeslami, M., Shehzad, S. A. \& Li, Z. 2018, Water based nanofluid free convection heat transfer in a three dimensional porous cavity with hot sphere obstacle in existence of Lorenz forces. International Journal of Heat and Mass Transfer, 125, 375-386.

Yuan, B., Yang, C., Mao, Z.-S., Yin, X. \& Koch, D. L. 2018, Heat/mass transfer from a neutrally buoyant sphere by mixed natural and forced convection in a simple shear flow. AIChE Journal, 64(7), 2816-2827.

Yuge, T. 1960, Experiments on heat transfer from spheres including combined natural and forced convection. Journal of Heat Transfer, 82, 214-220. 